\title{
The Regulation of Transcription in Memory Consolidation
}

\author{
Cristina M. Alberini ${ }^{1}$ and Eric R. Kandel $\left.\right|^{2,3,4,5,6}$ \\ ${ }^{1}$ Center for Neural Science, New York University, New York, New York 10003 \\ ${ }^{2}$ Zuckerman Mind Brain Behavior Institute, New York State Psychiatric Institute, New York, New York 10032 \\ ${ }^{3}$ Department of Neuroscience, New York State Psychiatric Institute, New York, New York 10032 \\ ${ }^{4}$ Kavli Institute for Brain Science, New York State Psychiatric Institute, New York, New York 10032 \\ ${ }^{5}$ Howard Hughes Medical Institute, New York State Psychiatric Institute, New York, New York 10032 \\ ${ }^{6}$ College of Physicians and Surgeons of Columbia University, New York State Psychiatric Institute, \\ New York, New York 10032 \\ Correspondence: ca60@nyu.edu; erk5@columbia.edu
}

De novo transcription of DNA is a fundamental requirement for the formation of long-term memory. It is required during both consolidation and reconsolidation, the posttraining and postreactivation phases that change the state of the memory from a fragile into a stable and long-lasting form. Transcription generates both mRNAs that are translated into proteins, which are necessary for the growth of new synaptic connections, as well as noncoding RNA transcripts that have regulatory or effector roles in gene expression. The result is a cascade of events that ultimately leads to structural changes in the neurons that mediate long-term memory storage. The de novo transcription, critical for synaptic plasticity and memory formation, is orchestrated by chromatin and epigenetic modifications. The complexity of transcription regulation, its temporal progression, and the effectors produced all contribute to the flexibility and persistence of long-term memory formation. In this article, we provide an overview of the mechanisms contributing to this transcriptional regulation underlying long-term memory formation.

$T^{\mathrm{h}}$ he ability to form long-term memories and to store them for periods ranging from days to weeks to a whole lifetime is one of the brain functions most critical for adaptation and survival. Without the ability to store information about our experiences for the long term, our lives would be a series of disconnected fragments. Memories shape our character and, thus, contribute to every aspect of our individuality. The process of long-term memory for- mation is complex and is accompanied by longlasting structural modification in the brain.

Long-term memories do not form immediately after learning but develop with time. They are initially fragile, but through a process of stabilization, known as memory consolidation, they become resistant to disruption (Bailey et al. 1996; McGaugh 2000; Dudai 2012). The biological mechanisms underlying consolidation start with a rapid phase of de novo gene

Editors: Eric R. Kandel, Yadin Dudai, and Mark R. Mayford

Additional Perspectives on Learning and Memory available at www.cshperspectives.org

Copyright (C) 2015 Cold Spring Harbor Laboratory Press; all rights reserved; doi: 10.1101/cshperspect.a021741

Cite this article as Cold Spring Harb Perspect Biol 2015;7:a021741 
expression, known as cellular or molecular consolidation. This begins at the onset of training and is a fundamental signature of long-term memory formation found in numerous species and in both explicit and implicit types of memories. Consolidation is manifest not only in behavior, but also in the cellular and molecular mechanisms contributing to long-term synaptic plasticity (Kandel 2001, 2014; Alberini 2009). Although it was long believed that molecular consolidation is completed rapidly, within a few hours, it recently emerged that in vivo it continues for at least $24 \mathrm{~h}$, a temporal window in which circadian rhythms and sleep may make an important contribution (EckelMahan and Storm 2009; Wang et al. 2011; Tononi and Cirelli 2014).

For example, in the hippocampus, a brain region critical for the formation of long-term contextual, spatial, and episodic memories, the gene expression-dependent phase necessary for the consolidation of inhibitory avoidance memory in rats lasts for more than $24 \mathrm{~h}$, and seems to be completed by $48 \mathrm{~h}$ after training (Taubenfeld et al. 2001b; Alberini 2009; Bekinschtein et al. 2014). In addition, through a subsequent process called system consolidation, the initial critical role of the hippocampus continues for up to weeks in mice and even up to years in humans, although, over time, it can become dispensable (Squire et al. 2004; Wiltgen and Tanaka 2013). As a result, memory loss can still occur weeks after training in animals, and even years in humans, when the hippocampus is either inactivated or ablated. At the end of this phase of system consolidation, memories become insensitive to disruption by either pharmacological or molecular manipulations or hippocampal disruption/inactivation, and are therefore considered consolidated at the system level. System consolidation is primarily found in hippocampus-based explicit memories. Implicit memories, such as emotional Pavlovian associations that require the amygdala (e.g., cued fear conditioning) undergo molecular consolidation, but they are not known to undergo system consolidation like the hippocampal-dependent ones. However, it is important to keep in mind that, although the distinction between implicit and explicit memory can be seen and studied in laboratory settings in which conditions can be controlled, different implicit and explicit memory processes generally interact to form long-term memories in real life (Phelps 2004).

It was long believed that the molecular/cellular phase of memory consolidation occurs only once, following training. Recently, however, we have learned that when memories that have become resistant to molecular interferences, hence, consolidated with respect to the molecular consolidation process are reactivated by a retrieval event, they can, as a result, become temporarily sensitive to disruption. During the first few hours after reactivation, de novo transcription and translation are required as is the case during consolidation. Only over time do the memories regain their stability and resilience. Because of the similarities with consolidation, this postreactivation process of stabilization is known as memory reconsolidation (Sara 2000; Alberini 2011; Nader and Einarsson 2010). The reconsolidation of different types of memories shows different temporal boundaries. Although hippocampal-based memories undergo a temporal gradient of stabilization for postretrieval interference and seem to become at one point resilient (Milekic and Alberini 2002; Suzuki et al. 2004; Frankland et al. 2006; Graff et al. 2014), amygdala-based memories can reconsolidate for a long time after training (Debiec et al. 2002, 2006). The reasons for this difference may very well reside in the different processing and mechanisms of the distinct memory systems. It is thought that hippocampal-cortical system consolidation may explain the temporal window during which these memories can undergo reconsolidation (Alberini 2011).

A fundamental biological mechanism for both consolidation and reconsolidation is de novo gene expression, and both processes recruit several overlapping mechanisms, including transcription factors and regulators. Thus, important questions to be understood are: How can DNA transcription promote memory stabilization? Are these changes in gene expression transient or do they last for weeks, months, or even years paralleling memory storage? This central issue has attracted the attention of many 
neuroscientists in the last two decades and has been investigated in in vitro models and a variety of behavioral paradigms in invertebrates as well as in mammals. These studies have asked: What regulatory mechanisms of transcription are involved in long-term memory formation? Can these changes in gene expression by themselves explain the long persistence of memories? What are the genes transcribed in response to the experience and what are their functions? Are these molecular mechanisms important therapeutic targets for treating memory disorders?

In this review, we summarize some of the current answers to these questions. Given the large number of studies, we will only be able to describe examples of (1) the major classes of transcription factors that play a critical role in both posttraining and postretrieval transcriptional regulation; (2) the target sequences regulated, including effector genes; and (3) the noncoding RNAs that have recently been found to regulate transcription and that can lead to chromatin, DNA, and RNA modifications that act in concert with transcription factors to regulate transcription important for memory consolidation.

\section{MEMORY CONSOLIDATION AND RECONSOLIDATION REQUIRE TRANSCRIPTION}

Transcription, the first step of gene expression, is the mechanism that copies a sequence of DNA into RNAs. It is a complex process that requires the concerted action of protein and RNA complexes that together dictate the expression of target genes. It is estimated that $5 \%-10 \%$ of the expressed sequences in the human genome encode for transcription regulators, which indicates the importance and complexity of regulating transcription. Transcription regulators include DNA-binding proteins that dictate the rate of gene transcription and are commonly known as transcription factors, cofactors that interact with transcription factors, chromatin regulators, the general transcription machinery, and their regulators. The complexity of transcription regulation implies the versatility, selec- tivity, and flexibility of the process, which, in fact, governs all cellular functions.

Studies using inhibitors of mRNA transcription in a variety of species ranging from invertebrates to mammals have shown that memory consolidation requires the synthesis of mRNAs and their translation into proteins, and that these transcriptional events are a fundamental and evolutionarily conserved mechanism of long-term memory formation (Brink et al. 1966; Agranoff 1967; Squire and Barondes 1970; Thut and Lindell 1974; Wetzel et al. 1976; Nestler 1993; Pedreira et al. 1996). As described earlier, memory consolidation recruits transcription and translation at multiple phases during an initial and limited temporal window. For example, in the rat hippocampus, a key region for explicit memory formation, at least two periods of transcription are needed to establish a long-term inhibitory avoidance memory. The first period of transcription occurs at about the time of training and the second occurs around 3-6 h later (Quevedo et al. 1999; Igaz et al. 2002). As mentioned earlier, the requirement for this initial transcription in the hippocampus continues for more than $24 \mathrm{~h}$ but ends by $48 \mathrm{~h}$ after training (Taubenfeld et al. 2001b; Garcia-Osta et al. 2006; Bekinschtein et al. 2007; Chen et al. 2011).

Another phase of transcription is required during reconsolidation. Although the underlying mechanisms are much less understood, it has been found that memory reactivation reinitiates a phase of gene expression, as revealed by the amnesia caused when either mRNA synthesis or the function of transcription factors is inhibited after retrieval (Sangha et al. 2003; Suzuki et al. 2004; Da Silva et al. 2008; Maddox et al. 2010; Cheval et al. 2012; Arguello et al. 2013). As in consolidation, the necessity of mRNA transcription in reconsolidation has been observed in many species ranging from invertebrates like Lymnaea stagnalis to mammals (Sangha et al. 2003; Suzuki et al. 2004; Merlo et al. 2005; Arguello et al. 2013; Veyrac et al. 2014), indicating its general and evolutionarily conserved role in the fragile phases of memory.

The important role of transcription has also been confirmed in cellular mechanisms con- 
tributing to long-term memory formation. These cellular mechanisms include long-lasting changes of the strength of synaptic connections in long-term facilitation (LTF) in the invertebrate Aplysia californica, and long-term potentiation (LTP) and long-term depression (LTD) in mammalian brain cells (Lynch 2004), thus strengthening the conclusion that transcription and gene expression are essential and general mechanisms necessary for stabilizing functions supported by long-term plasticity.

\section{CLASSES OF TRANSCRIPTION FACTORS INVOLVED IN LONG-TERM MEMORY CONSOLIDATION}

Since the initial studies of the 1990s on the identification of transcription factors required for long-term plasticity and memory, it has emerged that one of the gene expression pathways required across species, types of memories, and memory systems for long-term plasticity and memory consolidation is that activated by cAMP-dependent mechanisms and mediated by members of the family known as cAMPresponse element-binding proteins (CREB) (Dash et al. 1990; Bourtchuladze et al. 1994; Yin et al. 1994; Bartsch et al. 1995; Silva et al. 1998; Scott et al. 2002; Yin and Tully 2006; Alberini 2009; Kandel 2012). In the invertebrates A. californica and Drosophila melanogaster, the activation of the cascade cAMP-protein kinase A (PKA)-CREB is critical for plasticity and memory formation (Yin et al. 1994; Kandel 2012; but see Perazzona 2004). Specifically, cAMP-PKA activation initiates short-term synaptic changes that subsequently link via nuclear translocation of PKA, ERK, and perhaps other kinases to the activation and recruitment of CREB proteins and gene transcription (Bacskai et al. 1993; Martin et al. 1997; Ch'ng et al. 2012). Most of these mechanisms are conserved in the mammalian brain where the CREB-dependent pathway has also been shown to be necessary for long-term memory formation and long-term synaptic plasticity (Benito and Barco 2010; Barco and Marie 2011). Moreover, the overexpression of CREB promotes long-term memory storage from protocols that otherwise only induce short-term memory indicating its proactive role (Josselyn et al. 2001; Barco et al. 2002; Josselyn and Nguyen 2005; Viosca et al. 2009; Gruart et al. 2012).

Although CREB represents one of the earliest identified transcription factors required for long-term memory formation, transcription regulation is a complex mechanism that involves the interactions of several transcription factors that can activate or inhibit transcription, cofactors, and general transcription proteins as well as chromatin-modifying proteins. In fact, CREB, like many other transcription factors, is expressed in many cell types throughout the organism, is regulated by several intracellular pathways, and is involved in several processes through different protein/chromatin complexes. CREB refers to the activator isoform, but the CREB family of transcription factors includes several members (such as CREB-2 and activating transcription factor [ATF-4]) that can act as inhibitors of transcription. Thus, its specific contribution to long-term memory formation is defined by the orchestrated regulation of the context in which CREB functions.

Hence, CREB, although essential, is one of several transcriptional events required for memory consolidation and reconsolidation. We next turn to examples of other transcription factors belonging to different families found to critically mediate memory consolidation and reconsolidation.

One gene controlled by and downstream from CREB activation in the context of learning or long-term plasticity is the CCAAT enhancer-binding protein $(\mathrm{C} / \mathrm{EBP})$, an immediate early gene (IEG) whose disruption or overexpression, like that of CREB, blocks or promotes long-term synaptic plasticity and long-term memory consolidation, respectively (Alberini et al. 1994; Lee at al. 2001; Taubenfeld et al. 2001a,b; Arguello et al. 2013). This indicates an intimate functional link between the two families of transcription regulators. One important aspect of this functional link is that via $\mathrm{C} / \mathrm{EBP}$, CREB controls a transcriptional cascade (Goelet et al. 1986; Alberini et al. 1994).

The biological implication of the contribution of a cascade of gene expression is that it 
governs a complex cellular function through a controlled and specific amplification of the initial signal. The result is a stable and long-lasting functional change that, at the same time, maintains flexibility and dynamism. Although the transcription factors of the cascade confer specificity through the ensemble of regulated target genes, chromatin and DNA modifications maintain the changes, as we will explain below (Guan et al. 2002; Levenson and Sweatt 2005). Additional signaling regulation can add, eliminate, or change the controllers of the cascades, thus turning on and/or off all of their downstream events, hence reversing or modifying the functional state of the cell. In fact, through specificity and cooperativity, gene-expression cascades lead to precise concerted actions.

Other transcription factors regulated as IEGs include the c-Fos and the zinc-finger protein Zif268 (also known as early growth response protein [EGR]-1). The transcription of these transcription factors is induced by activity following learning and play a necessary role in long-term memory formation (Guzowski 2002). Zif268 in particular is required in a variety of brain regions for consolidation and reconsolidation of different forms of explicit memories (Veyrac et al. 2014).

Understanding the transcriptional events underlying long-term plasticity and memory formation also provides important tools for asking further molecular questions. For example, in addition to experiments of knockout/ knockdown or functional blockade of IEGs, which leads to the identification of their role in plasticity and memory, the detection of activity-induced expression of c-Fos and Zif268 can be used as a survey of activity patterns elicited by learning, retrieval, or any behavioral response of interest. Furthermore, the IEG regulatory elements (e.g., promoter regions) can be used to build readouts of activity-dependent responses. For instance, constructs can be engineered using a c-Fos promoter placed in front of the tetracycline transactivator (tTA or TEToff ), which is known to drive the induction of tTA during high-level neural activity. tTA is a transcription factor that can be blocked by the antibiotic doxycycline (Dox), but, when ex- pressed, it drives the transcription of genes controlled by a tetO promoter. The presence of a second transgene carrying a tetO-linked reporter, like the somato-axonal marker tau-lacZ together with elements of stabilization, has been used to reveal c-fos promoter-driven active cellular networks. This approach (developed by Mayford and colleagues) has been used to reveal the map of neural networks activated by and responding to experience and processing of representations (Reijmers et al. 2007). The induction of c-fos during learning can also be utilized to selectively express a receptor that can regulate activity when desired. With this method, artificial memory traces can be created. For example, by artificially activating an ensemble of cells in a given context (e.g., context B), which earlier had been activated by the exposure to a different context (e.g., context A), one can create a hybrid, artificial memory representation (Garner et al. 2012; Ramirez et al. 2013). These studies show the importance of understanding and using the transcriptional mechanisms underlying memory formation and storage to develop novel strategies that can be useful in research as well as translational applications.

In addition to these classical IEGs, other classes of transcription factors play critical roles in long-term memory. These include the nuclear factor- $\kappa$ light-chain enhancer of activated $B$ cells $(N F-\kappa B)$, members of the families nuclear receptor $4 \mathrm{a}$ (NR4a), serum response factor (SRF), and neuronal Per-Arnt-Sim (PAS) homology factor 4 (NPAS4), just to mention a few. NF- $\kappa$, expressed in both neurons and glia, is induced by LTP and by learning tasks like water maze, novel object recognition, and contextual fear conditioning. Its knockout results in memory impairment indicating that it plays a critical role in memory-related synaptic plasticity (Kaltschmidt et al. 2006; Romano et al. 2006; Ahn et al. 2008; Crampton and O'Keeffe 2013; Snow et al. 2013). An interesting feature of NF- $\kappa \mathrm{B}$ is its synaptic localization, which implies that it plays a dual role in long-term memory, first as a signaling molecule at the synapse and second as a transcriptional regulator on translocation into the nucleus (Romano et al. 2006). In line with the functional requirement 
in memory consolidation and reconsolidation, primary functions targeted by family members of the NF- $\mathrm{BB}$ are the growth and morphological changes of axonal and dendritic arbors in several regions of the developing and mature central nervous system (CNS) (de la Fuente et al. 2011; Gutierrez and Davies 2011).

The nuclear receptor (NR) superfamily of transcription factors includes ligand-activated transcription factors implicated in cell differentiation, development, proliferation, and metabolism. They contain a zinc-finger DNA-binding domain and a carboxy-terminal ligand-binding domain. The expression of some members of this superfamily, including the NR4a family of orphan receptors, increases in the hippocampus immediately after learning, and their function is necessary for hippocampus-dependent contextual fear and object recognition memory as well as the transcriptional-dependent LTP (Bridi and Abel 2013). Notably, the level of NR4a increases following treatments that inhibit histone deacetylase (HDAC) (Hawk et al. 2012), a modification of histones that favors gene expression and promotes memory enhancement, as discussed below. Blocking NR4a signaling blocks the HDAC inhibitor-mediated memory enhancement suggesting that the $\mathrm{Nr} 4 \mathrm{a}$ gene family significantly contributes to memory consolidation and enhancement (Pena de Ortiz et al. 2000; Hawk and Abel 2011; Hawk et al. 2012; Bridi and Abel 2013).

SRF, like CREB, is a major controller of IEG expression associated with actin-mediated contractile and motile cell functions (Knöll and Nordheim 2009). In adult brain, SRF is required for the acquisition of novel contextual information and for hippocampal-dependent spatial memory, as well as for LTP and LTD (Ramanan et al. 2005; Etkin et al. 2006). SRF, expressed mostly in neurons but not in glia, regulates activity-dependent gene expression, neuronal precursor cell migration, and morphological differentiation in both the developing and adult neurons. Its downstream signal activation recruits MAPKs, CaM kinases, and Rho/actin signaling cascades. SRF is required for long-lasting cellular changes because it modulates actin microfilament dynamics and associated mor- phological functions. Thus, SRF seems to be positioned to couple the initial neural activation with the structural cell and synaptic modifications required for long-term maintenance of synaptic connections. SRF target genes include $c$-fos, Egr1, Egr2, and SRF itself as well as actin cytoskeletal genes (e.g., Acta1, Actb, Actg2) (Knöll and Nordheim 2009). Like CREB, SRF can recruit different cofactors and binding proteins, which can lead to either activation or repression of target genes; but, unlike CREB, it seems not to be involved in cell survival or apoptosis.

Although many transcription factors, such as CREB, c-Fos, Zif268, and NF- $\mathrm{BB}$, are expressed throughout the brain in a variety of different cell populations, other transcription factors involved in memory formation appear to have expression that is restricted to a subpopulation of cells. One example is NPAS4, a b-helix-loop-helix-PAS transcription factor induced by neuronal activity, which on heterodimerization with ARNT2 regulates genes involved in inhibitory synapse formation. Both the expression and activity of NPAS4 are tightly coupled to neuronal activity; neuronal depolarization, ischemia, seizure, and learning, all rapidly and transiently induce the expression of NPAS4, which, in turn, regulates the expression of genes involved in increasing the number of inhibitory synapses, thus maintaining homeostasis of neuronal activity (Lin et al. 2008; Kim et al. 2010). Because of its role in supporting inhibitory synapse formation, deletion of NPAS4, not surprisingly, results in glutamate neurotoxicity and neurodegeneration, hyperactivity, seizures, anxiety, and cognitive impairments. Some of these phenotypes are reminiscent of those found in autism and schizophrenia (Lin et al. 2008; Coutellier et al. 2012). Interestingly, conditional deletion of NPAS4 selectively in the CA3 region of the hippocampus in adult mice impairs contextual memory formation (Ramamoorthi et al. 2011). Furthermore, environmental experience leads to expression of NPAS4 in hippocampal pyramidal neurons, which promotes an increase of inhibitory synapses on the cell soma but a decrease in the number of inhibitory synapses on the 
apical dendrites. This differential regulation of somatic and apical dendritic inhibition may allow compartmental integration or plasticity (Bloodgood et al. 2013).

These are only a few examples of transcription factors belonging to different families critically implicated in memory consolidation and reconsolidation. They provide a flavor of how complex the transcription regulation responding to experience and mediating memory consolidation and reconsolidation is. Each of them in different combinatorial complexes regulates distinct sets of target genes that also remain differentially expressed over time. Because of their role in regulating activity-induced gene expression, the transcription factors involved in various brain functions, including learning and memory, are also implicated in a number of neuropsychiatric and neurodegenerative diseases.

\section{CHROMATIN STRUCTURAL ALTERATIONS ASSOCIATED WITH LONG-TERM MEMORY}

Transcription factors are key regulators of transcription, but they can only function if the appropriate DNA regulatory sequences are accessible to them. The gatekeepers of these regulatory sequences are the histone proteins around which the DNA is wrapped and that mediate compaction or relaxation of DNA sequences. In the nucleus of eukaryotic cells, the DNA complexes with histone proteins (also known as chromatin) form compact structures called nucleosomes, which are similar to beads on a necklace. Histone proteins have small tails that, by protruding from the nucleosome, offer themselves for the addition of specific marks on individual amino acids. The chromatin changes, which include histone posttranslational modifications, chromatin remodeling, and histone variant exchange, produce a unique combination or code that controls the way the DNA is packaged, hence available for transcription. Tight packaging inhibits DNA accessibility to the transcription machinery, whereas loose packaging allows DNA sequences to be accessible for transcription. In addition to chromatin changes, there are also chemical modifications of the
DNA itself, which together are referred to as "epigenetic changes" that regulate the availability and temporal duration of gene expression.

The discovery that the requirement for de novo gene expression is necessary for memory consolidation and reconsolidation first suggested that epigenetic changes must play essential roles. As morphological changes in synaptic structures have been found to correlate with the persistence of memory retention (Aplysia, mammals, songbirds), it is thought that the persistence of patterns of gene expression, hence the organization of chromatin and DNA modifications, orchestrate and control information retention by regulating transcription that translates into synaptic structural changes.

Until around the year 2000, chromatin modification had been studied primarily in the context of development and differentiation. Despite extensive studies of transcription in the brain, little was known about whether external events that affect transcription modulate chromatin structure in neurons.

Swank and Sweatt (2001) were the first to suggest that histone modifications may play a role in regulating gene expression associated with long-term memory formation.

The demonstration that histone acetylation was indeed a critical step for the de novo gene expression required for long-term plasticity mechanisms came in 2002 from Guan et al. who explored chromatin structure and protein-DNA interaction in Aplysia neuronal cultures in the context of learning-related synaptic plasticity using chromatin immunoprecipitation. The investigators focused on the chromatin around the promoter of C/EBP, which, as we have seen, is an early response gene downstream from CREB-1 with several CRE elements in the promoter region. C/EBP is rapidly induced during the formation of long-term memory and its induction is critical for long-term synaptic plasticity and memory (Alberini et al. 1994). Preventing the induction of C/EBP blocks LTF, whereas overexpression of C/EBP enhances LTF.

Guan et al. (2002) found that when Aplysia was exposed to repeated pulses of serotonin (5$\mathrm{HT}$ ), a protocol that induces long-term memory as a result of CREB and C/EBP expression, the 
CREB-binding protein (CBP), which is capable of binding to CREB1, was recruited to the promoter of C/EBP to form a CREB1-CBP complex. In addition to CREB1, a small amount of CREB2 - an inhibitor of CREB1-is bound to the promoter in the untreated state, and this small amount of CREB-2 decreases further after 5-HT exposure. This decrease in CREB2 most likely represents a displacement of CREB2 from the promoter after serotonin induction. With the induction of the C/EBP, the TATA-box-binding protein is also recruited to the promoter.

Guan et al. (2002) next asked whether the induction of C/EBP involves regulation of histone acetylation. They found that, indeed, exposure to repeated pulses of serotonin increased the acetylation of both histone $\mathrm{H} 3$ and $\mathrm{H} 4$ at the $\mathrm{C} / \mathrm{EBP}$ promoter. Unlike $\mathrm{H} 3$, there was a strong basal acetylation of $\mathrm{H} 4$ in untreated animals. Both histone $\mathrm{H} 3$ and $\mathrm{H} 4$ have several lysine residues that can be acetylated. Guan et al. (2002) found that the acetylation and deacetylation of histones at the $\mathrm{C} / \mathrm{EBP}$ promoter correlated with the induction and the termination of $\mathrm{C} / \mathrm{EBP}$ expression.

Guan et al. (2002) next went on to ask: How are the excitatory and inhibitory inputs on a simple neuron integrated into a coherent output? Although the question of synaptic integration has been much studied, little was known about how neurons sum up opposing signals for long-term synaptic plasticity and memory. To address this question, they studied the same Aplysia sensory neurons that undergo LTF in response to serotonin. These neurons also undergo long-term synaptic depression in response to the peptide transmitter FMRFamide. Each of these transmitters produces synapsespecific actions when applied to one set of terminals and not the other. But when experimenters applied to the sensory neurons simultaneous pulses of the facilitating transmitter serotonin at one of the set of terminals while applying inhibitory transmitter FMRFamide at the other set of terminals, long-term synaptic depression dominated and shut off LTF, centrally preventing it from being expressed.

They next used chromatin immunoprecipitation assays and found that, although seroto- nin induces the transcription of C/EBP through CREB1 activation and CBP recruitment with the consequent increase of histone acetylation, FMRF leads to CREB1 displacement by CREB2 and the recruitment of histone deacetylase 5 (HDAC5). When the two transmitters are applied together, facilitation is blocked and CREB2 and HDAC5 displace CREB1-CBP thereby deacetylating histones (Fig. 1). These studies show that long-term integration of spatially separate inhibitory and excitatory synaptic inputs occurs in the nucleus and is achieved by regulating chromatin structure and gene induction bidirectionally. Inhibitory inputs dominate in long-term integration by overriding the effects of facilitatory inputs on histone acetylation and gene induction. Thus, a neuron integrates opposite inputs at several levels: on the cell membrane to determine short-term response and in the nucleus to determine long-term response.

In subsequent years, many studies have investigated the mechanisms of chromatin and DNA modifications that, together with the recruitment of specific transcription complexes, regulate gene expression in the brain, and particularly in plasticity, learning and memory, reward, and cognitive processes in general (for reviews, see Maze et al. 2013; Peixoto and Abel 2013). Below, we limit our description to a few examples of chromatin regulators that have been found to critically control gene expression in memory formation through the action of some of the transcription factors that we have described above as essential in memory consolidation.

Because the consolidation and reconsolidation of different types of memories use different memory systems and are mediated by different brain regions, it is likely that different patterns of chromatin and DNA modifications occur in a cell-specific manner and differentially evolve over time. It follows that, to understand memory consolidation at the level of gene expression, it is necessary not only to identify the learninginduced pattern of expressed genes but also the learning-induced combinatorial interaction and assembly of transcription factors, cofactors, chromatin modifications, and remodeling as well as DNA modifications that control gene 
Transcription in Memory Consolidation

A Control

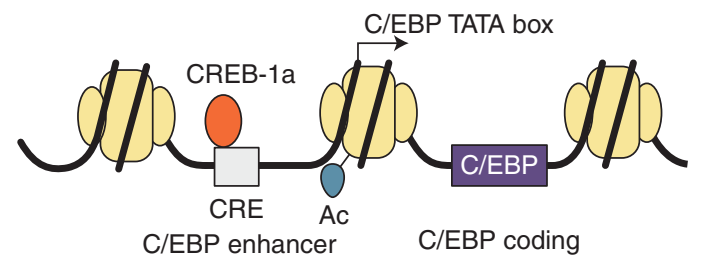

B 5-HT alone

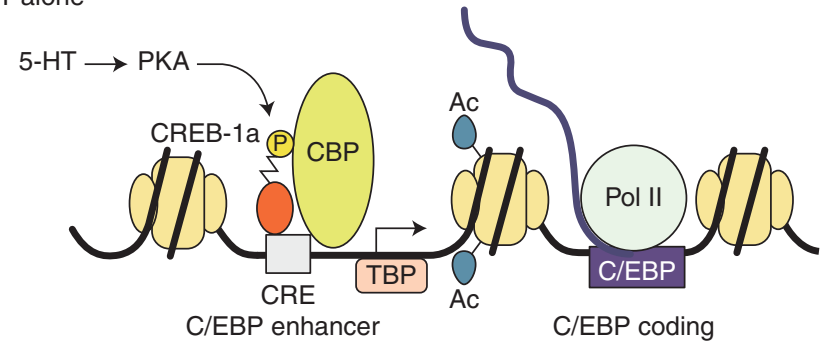

C FMRFa alone
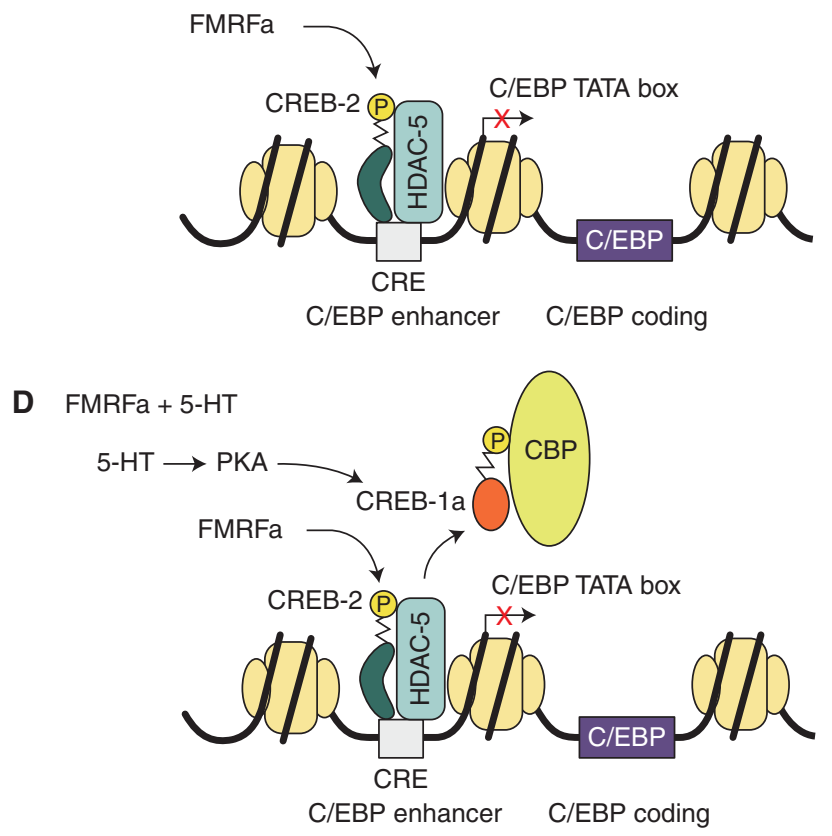

Figure 1. How 5-HT and FMRFa bidirectionally regulate chromatin changes leading to c/ebp transcription. $(A)$ At the basal level, CREB1a resides on the C/EBP promoter; some lysine residues of histones are acetylated. $(B)$ 5-HT, through PKA, phosphorylates CREB1 that binds to the C/EBP promoter. Phosphorylated CREB1 then forms a complex with CBP at the promoter. CBP then acetylates lysine residues of the histones (for example, K8 of $\mathrm{H} 4)$. Acetylation modulates chromatin structure, enabling the transcription machinery to bind and regulate gene expression. $(C)$ FMRFa activates CREB2, which displaces CREB1 from the C/EBP promoter. HDAC5 is then recruited to deacetylate histones. As a result, the gene is repressed. $(D)$ If the neuron is exposed to both FMRFa and 5-HT, CREB1a is replaced by CREB2 at the promoter even though it might still be phosphorylated through the 5-HT-PKA pathway, and HDAC5 is then recruited to deacetylate histones, blocking gene induction (from Guan et al. 2002). 
expression in a comprehensive way rather than in isolation. Moreover, as memory consolidation and reconsolidation evolve and change with time, allowing memory storage to be dynamic, the temporal evolution of the underlying molecular changes needs to be understood to comprehend how memory consolidation, persistence, and storage occur.

Although this complexity has thus far prevented the elucidation of a comprehensive picture, specific types of chromatin changes that in the brain play a critical role in memory formation and storage have been identified. Removing or adding acetyl groups from histones, through the action of HDACs or histone acetyltransferases (HATs), respectively, modifies the histones wrapping around the DNA, thus influencing gene expression. In rodent brain, changes in histones acetylation occur in response to protocols that induce late LTP (L-LTP), a form of long-term plasticity that, like memory consolidation, requires transcription (Weaver et al. 2004; Levenson and Sweatt 2006); and HDAC inhibitors promote memory formation and enhancement (Rudenko and Tsai 2014). Although the identification of the specific mechanisms that mediate the memory-enhancing effect of HDAC inhibitors is still in progress, HDAC2 seems to have an important role (Guan et al. 2009; Morris et al. 2013). Furthermore, and once again evolutionarily conserved, the recruitment of the HAT CBP controls the gene expression critical for plasticity and memory consolidation and enhancement (Alarcon et al. 2004; Korzus et al. 2004; Wood et al. 2006). As promoting CREB activation in CBP mutant mice rescues their memory impairment phenotypes, it follows that, as discussed above, CREB-dependent gene expression indeed plays a primary and proactive role in long-term memory formation (Bourtchouladze et al. 2003). Clinical data also underscore this conclusion, as mutations of CBP, or the related protein $\mathrm{p} 300$, are associated with devastating cognitive impairments, like that of the Rubinstein-Taybi syndrome. In animal models of Rubinstein-Taybi and in cell lines derived from Rubinstein-Taybi syndrome patients, cognitive impairments and histone acetylation defects can be ameliorated by
HDAC inhibitors (Alarcon et al. 2004; LopezAtalaya et al. 2012; Park et al. 2014).

Genetic mutations of mice have shown that most classes of HDAC are involved in memory formation and its accompanying regulation of the IEG. For example, the class I HDAC1 and 3 bidirectionally modulate memory retention and regulate the expression of IEGs like c-Fos, NR4a, and Zif268. On the other hand, another class I HDAC, the HDAC2, acts as a negative regulator of memory formation by binding to the promoter regions of numerous regulatory genes, including Zif268, CREB, CBP, and effector genes like Homer1, Arc, GLUA1/2, NR2A/2B, Nrx1/ 3, Shank3, and PSD95 (Guan et al. 2009).

In addition to chromatin changes, longterm memory formation also depends on DNA methyltransferases (Miller and Sweatt 2007), indicating that chemical DNA modifications are also fundamental for the process (see Jarome and Lubin 2013, Zovkic et al. 2013, and Rudenko and Tsai 2014 for more information).

\section{NONCODING RNAS IN THE REGULATION OF TRANSCRIPTION}

mRNAs are not the only target of transcription and chromatin regulation in memory consolidation and reconsolidation. Noncoding RNAs, like micro-RNAs (miRNAs), PIWI-interacting RNAs (piRNAs), and long noncoding RNAs (ncRNAs), are also targeted, and their expression in turn regulates transcriptional and posttranscriptional mechanisms. To obtain an understanding of how chromatin structure might be regulated, Rajasethupathy et al. (2012) performed a systematic screen of small RNAs in Aplysia. They found that there were not one but two classes of small RNAs regulated by neural activity: miRNAs and piRNAs. MiRNAs are a class of conserved 20-23-nucleotide noncoding RNAs that, in turn, critically contribute to transcriptional and posttranscriptional regulation of gene expression and depend on the RNAi machinery for maturation and function. Rajasethupathy et al. (2012) identified 170 distinct miRNAs: nine of these were enriched in the brain and several were down-regulated by sero- 
Library of small RNAs from CNS revealed that in addition to miRNAs, Aplysia has piRNA in the brain
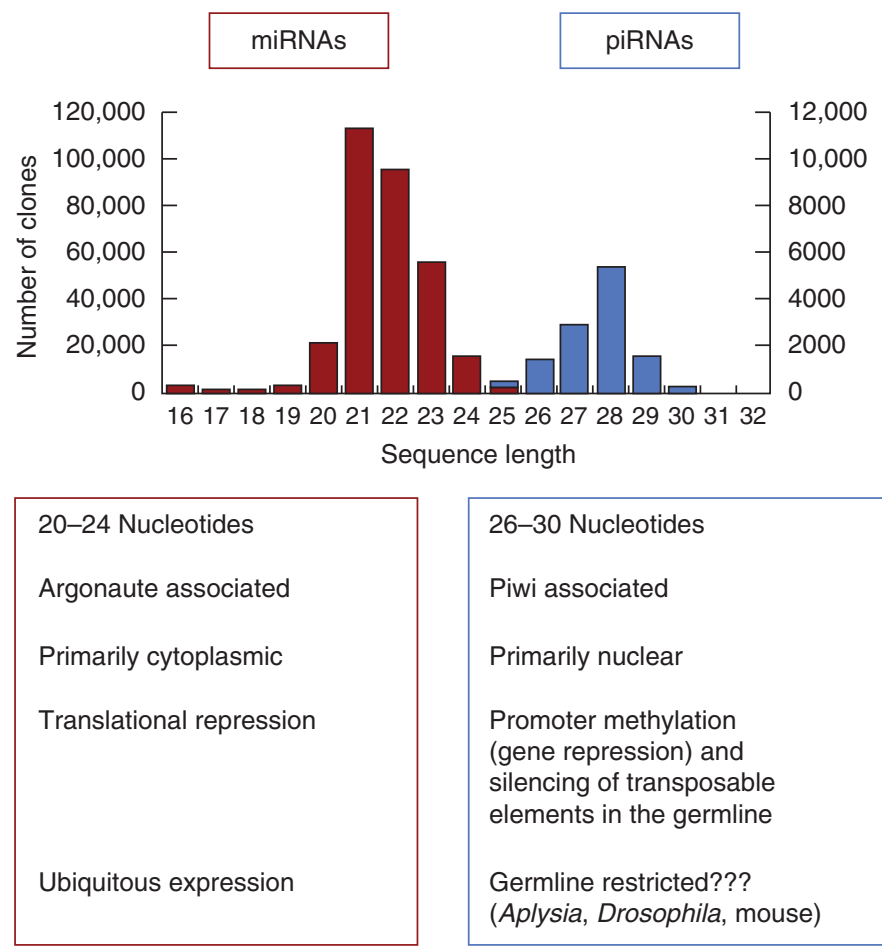

Figure 2. Two classes of small RNAs in Aplysia central nervous system (CNS). A size histogram of the cloned small RNAs revealed two populations, and further characterization confirmed the new class of sequences (blue) to be piRNAs.

tonin, the modulatory transmitter released during learning (Fig. 2).

Characterization of these neural-enriched miRNAs revealed that miRNA 124, the most abundant and conserved brain-specific miRNA, was exclusively present presynaptically in the sensory-to-motor synapse, where it constrained serotonin-induced synaptic facilitation through the regulation of the mRNA of the transcription factor CREB1. The activation of serotonin inhibits miRNA 124, thereby disinhibiting the translation of CREB1 making possible longterm transcription.

But in addition to miRNAs, Rajasethupathy made the surprising discovery of a second class of small noncoding RNA molecules, piRNAs, 28 to 32 nucleotides in length previously thought to be restricted to germ cells (Fig. 2). One of these piRNAs-piRNA-F-increased in re- sponse to serotonin and led to the methylation of the promoter of CREB2 and to its silencing. Thus, serotonin regulates both piRNAs and miRNAs in a coordinated fashion, illustrating the integrative interactive action of small RNAs on the transcriptional level. Serotonin inhibits miRNA 124 rapidly and facilitates the activation of CREB1, which begins the process of memory consolidation, whereas piRNA-F, also activated by serotonin but with a delay, leads to methylation and thus repression of the promoter CREB2, allowing CREB1 to be active for a longer period of time, thereby establishing a stable long-term change in the sensory neuron that consolidates memory and puts it into the long-term phase (Fig. 3).

Examples of miRNA regulation have also been found in mammalian memory consolidation and plasticity. For example, the class III 
C.M. Alberini and E.R. Kandel

A New view of the consolidation switch

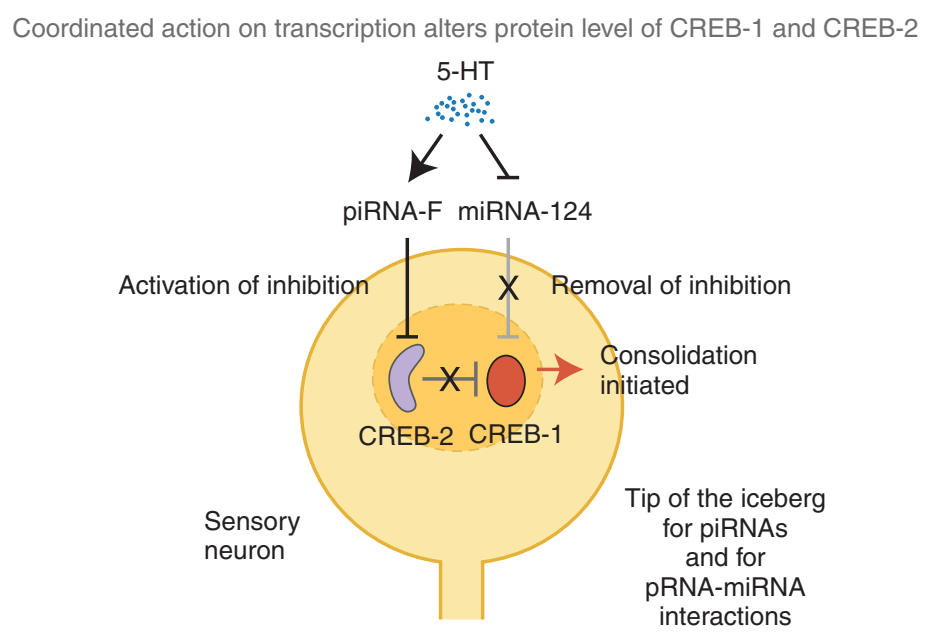

Figure 3. Epigenetic regulation of the transcriptional switch. 5-HT inhibits miRNA-124 and thus facilitates the activation of CREB-1, which begins the process of memory consolidation, whereas piRNA, also activated by 5-HT but with a delay, methylates and thus represses the promoter of CREB-2, allowing CREB-1 to be active for a longer period of time.

NAD-dependent deacetylase SIRT1 limits the transcription of the miRNA 134, which represses the expression of critical plasticity/memoryrelated genes, such as creb and $b d n f$, hence promoting and regulating memory retention (Gao et al. 2010). Overexpression or inhibition of miRNA-132 in forebrain neurons, respectively, increases or reduces spine density (Hansen et al. 2010; Magill et al. 2010) and miRNA-132 accumulates in response to activity (Nudelman et al. 2010). Furthermore, miRNA-132 also inhibits methyl-CpG-binding protein 2 ( $\mathrm{MeCP} 2$ ), a regulator of transcription that binds to methylated DNA (Klein et al. 2007). Long ncRNAs can target different aspects of transcription regulation by modulating transcriptional activators or repressors, different components of the transcription reaction, such as RNA polymerase (RNAP) II, and even the DNA structure (Goodrich and Kugel 2006). NcRNAs modulate the function of transcription factors by several mechanisms, including by functioning themselves as coregulators, modifying transcription factor activity, or regulating the association and activity of coregulators. Hence, it is speculated that ncRNAs, which together with transcription factors, chromatin, and DNA modifica- tions, finely control gene expression in complex eukaryotes and may have a critical role in regulating gene expression in memory consolidation and reconsolidation (Mercer et al. 2008).

\section{AN OVERALL VIEW: THE FUNCTIONAL OUTCOME OF TRANSCRIPTION IN MEMORY STABILIZATION AND STORAGE}

As mentioned earlier, understanding transcription underlying complex brain functions, such as memory consolidation and reconsolidation, requires the characterization of the complexity of the underlying mechanisms, including modification of DNA and chromatin, activation or inhibition of the expression of transcription factors, formation of diverse DNA-binding complexes that regulate gene expression, transcription regulation of target genes, which include those translated into proteins and regulatory sequences, such as miRNAs and ncRNAs, and further downstream changes, including transport, translation, and activation of the effector genes.

What is the role of this complexity in the stabilization processes of consolidation and reconsolidation? Why is transcription regulation 
required for memory stabilization? Given the complexity of memory storage, a clear answer is not yet available. Most information we have relates to single pathways, cell types, or restricted temporal windows. However, we have attempted to provide some answers given the knowledge that is available.

First, de novo gene expression is required for memory stabilization because it provides a controlled mechanism for inducing cellular changes that can persist for a long time, in fact, establishing a pattern of gene expression governed by the epigenome determines cellular changes that last as long as the epigenomic and transcription factor activation are maintained. Second, it offers specificity, as specific changes can occur through the selection of programs of gene expression. For example, in line with the accepted view of long-term synaptic plasticity, if the number and/or type of synaptic contacts change in response to learning, and this synaptic network constitutes the site where information is stored, then gene expression would be able to provide all the proteins, and only those, necessary to build and sustain those long-lasting synaptic changes. Hence, de novo gene expression is indeed an ideal underlying mechanism, because it offers regulated changes and stability and at the same time a vast repertoire of combinatorial possibilities for rapid responses to the changing environment. In other words, transcription regulation can provide a mechanism and explanation for the dynamic nature of memory storage. The complexity of the gene expression repertoire also allows for integration of information. Third, gene expression is different in different cell types (e.g., inhibitory versus excitatory neurons/synapses or versus astrocyte, microglia, oligodendocytes), and together the cell-specific patterns of gene expression can produce distinct functional integration patterns. These combinatorial patterns of gene expression translate into cellular functions, which then result in the cross talk among different brain areas that underlie memory consolidation, reconsolidation, and storage. Hence, transcription and gene-expression mechanisms can also explain how information can be stored in a system-wide dynamic network. It has, in fact, become increasingly clear that memory storage is not a fixed function, but rather is a very dynamic process, whereby consolidation and reconsolidation together with possibly other retrieval-dependent processes and multiple trace consolidation/ reconsolidation play a role in maintaining and changing information over time (Alberini 2011; Inda et al. 2011; Alberini et al. 2012).

System-wide molecular changes clearly must involve numerous forms of modification, cooperation, and regulations. Thus, one can ask: What types of cellular functions reflect the outcome of the transcription required for memory stabilization? A reasonable answer is that, given that memory consolidation and reconsolidation are the result of a network involving several brain regions, it is likely that the underlying transcriptional mechanism regulates both general as well as brain region- or cell-specific events. The field of transcription regulation in long-term memory is relatively new and, as a first step, in the last $20-25 \mathrm{yr}$, has mainly focused on identifying general, common mechanisms of cellular and synaptic plasticity. Here we will mention two examples of these general mechanisms that are mediated by CREB: the regulation of excitability and activation of growth pathways and related structural changes.

Overexpression of CREB in neurons promotes their preferential recruitment into a fear memory trace (Han et al. 2007). Specifically, if neurons in the amygdala of mice overexpress CREB, they are more likely to be activated, as revealed by IEG expression, following fear conditioning testing. This suggested that the CREBoverexpressing neurons are predisposed to participate in the memory trace and possibly that the system is not hardwired at the level of individual neurons but that certain molecular states of neurons, such as those promoted by CREB overexpression, favor a neuron's recruitment into the memory trace. Furthermore, selective ablation of the CREB-overexpressing neurons disrupts the fear memory, whereas ablation of a similar number of random neurons in the amygdala has no effect, demonstrating their functional role in memory formation and storage (Han et al. 2009). One of the general functions promoted by CREB expression seems to 
be neuronal excitability (Lopez de Armentia et al. 2007; Viosca et al. 2009; Zhou et al. 2009; Tong et al. 2010; Gruart et al. 2012) and, like the overexpression of CREB, increased excitability promotes cellular recruitment (allocation) in long-term memory (Rogerson et al. 2014) leading to the conclusion that CREB-dependent gene expression governs the circuitry recruited in memory formation and storage by increasing neuronal excitability.

Another general function regulated by CREB-dependent pathways that may contribute to cellular changes required for memory stabilization is growth (Persengiev and Green 2003). Growth pathways are activated in response to experience and play a key role in neurons during long-term memory formation. CREB is required to regulate the expression of growth factors, such as the brain-derived neurotrophic factor (BDNF), which plays a central role in the induction and maintenance of long-term plasticity and long-term memory and is a critical mediator of synaptic structural changes (Lu et al. 2008). Hence, a plausible hypothesis is that transcription regulated by CREBs controls growth as a fundamental outcome of longterm plasticity and memory (Alberini 2009; Kida 2012; Finsterwald and Alberini 2013; Nestler 2013).

These are only two examples thus far characterized, but given the critical role of de novo transcription in long-term memory, it is important that it be fully understood. Despite the great progress made in the last $25 \mathrm{yr}$, the understanding of transcription regulation in long-term memory is clearly in its infancy. A number of questions remain to be addressed including: What is the contribution of transcription regulation in long-term memory from each cell type and brain region? How does transcription alter each cell involved? Which are the end products? Are they general or selective in different cells? What is general or selective in different types of memories? How does previous experience change the learning-dependent transcriptional regulation? The answers to these questions will come from future studies and this knowledge will also be critical for a better understanding of memory disorders.

\section{REFERENCES}

Abel T, Havekes R, Saletin JM, Walker MP. 2013. Sleep, plasticity and memory from molecules to whole-brain networks. Curr Biol 23: R774-R788.

Agranoff BW. 1967. Agents that block memory. In The neurosciences: A study program. Rockefeller University Press, New York.

Ahn HJ, Hernandez CM, Levenson JM, Lubin FD, Liou HC, Sweatt. 2008. c-Rel, an NF-кB family transcription factor is required for hippocampal long-term synaptic plasticity and memory formation. Learn Mem 15: 539-549.

Alarcón JM, Malleret G, Touzani K, Vronskaya S, Ishii S Kandel ER, Barco A. 2004. Chromatin acetylation, memory, and LTP are impaired in $\mathrm{CBP}^{+/-}$mice: $\mathrm{A}$ model for the cognitive deficit in Rubinstein-Taybi syndrome and its amelioration. Neuron 42: 947-959.

Alberini CM. 2009. Transcription factors in long-term memory and synaptic plasticity. Physiol Rev 89: 121-145.

Alberini CM. 2011. The role of reconsolidation and the dynamic process of long-term memory formation and storage. Front Behav Neurosci 5: 12.

Alberini CM, Ghirardi M, Metz R, Kandel ER. 1994. C/EBP is an immediate-early gene required for the consolidation of long-term facilitation in Aplysia. Cell 76: 1099-1114.

Alberini CM, Johnson SA, Ye X. 2012. Mechanisms and functions of memory reconsolidation: Lingering consolidation and the dynamic memory trace. In Memory reconsolidation (ed. Alberini CM). Academic, New York.

Arguello AA, Ye X, Bozdagi O, Pollonini G, Tronel S, Bambah-Mukku D, Huntley GW, Platano D, Alberini CM. 2013. CCAAT enhancer binding protein $\delta$ plays an essential role in memory consolidation and reconsolidation. $J$ Neurosci 33: 3646-3658.

Bacskai BJ, Hochner B, Mahaut-Smith M, Adams SR, Kaang B-K, Kandel ER, Tsien RY. 1993. Spatially resolved dynamics of cAMP and protein kinase A subunits in Aplysia sensory neurons. Science 260: 222-226.

Bailey CH, Bartsch D, Kandel ER. 1996. Toward a molecular definition of long-term memory storage. Proc Natl Acad Sci 93: 13445-13452.

Barco A, Marie H. 2011. Genetic approaches to investigate the role of CREB in neuronal plasticity and memory. Mol Neurobiol 44: 330-349.

Barco A, Alarcon JM, Kandel ER. 2002. Expression of constitutively active CREB protein facilitates the late phase of long-term potentiation by enhancing synaptic capture. Cell 108: 689-703

Bartsch D, Ghirardi M, Skehel PA, Karl KA, Herder SP, Chen M, Bailey CH, Kandel ER. 1995. Aplysia CREB2 represses long-term facilitation: Relief of repression converts transient facilitation into long-term functional and structural change. Cell 83: 979-992.

Bekinschtein P, Cammarota M, Igaz LM, Bevilaqua LR, Izquierdo I, Medina JH. 2007. Persistence of long-term memory storage requires a late protein synthesis- and BDNF- dependent phase in the hippocampus. Neuron 53: 261-277.

Bekinschtein P, Cammarota M, Medina JH. 2014. BDNF and memory processing. Neuropharmacology 76: 677683. 
Benito E, Barco A. 2010. CREB's control of intrinsic and synaptic plasticity: Implications for CREB-dependent memory models. Trends Neurosci 33: 230-240.

Bloodgood BL, Sharma N, Browne HA, Trepman AZ, Greenberg ME. 2013. The activity-dependent transcription factor NPAS4 regulates domain-specific inhibition. Nature 503: 121-125.

Bourtchuladze R, Frenguelli B, Blendy J, Cioffi D, Schutz G, Silva AJ. 1994. Deficient long-term memory in mice with a targeted mutation of the cAMP-responsive elementbinding protein. Cell. 79: 59-68.

Bourtchouladze R, Lidge R, Catapano R, Stanley J, Gossweiler S, Romashko D, Scott R, Tully T. 2003. A mouse model of Rubinstein-Taybi syndrome: Defective longterm memory is ameliorated by inhibitors of phosphodiesterase 4. Proc Natl Acad Sci 100: 10518-10522.

Bridi MS, Abel T. 2013. The NR4A orphan nuclear receptors mediate transcription-dependent hippocampal synaptic plasticity. Neurobiol Learn Mem 105: 151-158.

Brink JJ, Davis RE, Agranoff BW. 1966. Effects of puromycin, acetoxycycloheximide and actinomycin D on protein synthesis in goldfish brain. J Neurochem 13: 889-896.

Chen DY, Stern SA, Garcia-Osta A, Saunier-Rebori B, Pollonini G, Bambah-Mukku D, Blitzer RD, Alberini CM. 2011. A critical role for IGF-II in memory consolidation and enhancement. Nature 469: 491-497.

Cheval H, Chagneau C, Levasseur G, Veyrac A, Faucon-Biguet N, Laroche S, Davis S. 2012. Distinctive features of Egr transcription factor regulation and DNA binding activity in CA1 of the hippocampus in synaptic plasticity and consolidation and reconsolidation of fear memory. Hippocampus 22: 631-642.

Ch'ng TH, Uzgil B, Lin P, Avliyakulov NK, O’Dell TJ, Martin KC. 2012. Activity-dependent transport of the transcriptional coactivator CRTC1 from synapse to nucleus. Cell 150: 207-221.

Coutellier L, Beraki S, Ardestani PM, Saw NL, Shamloo M. 2012. Npas4: A neuronal transcription factor with a key role in social and cognitive functions relevant to developmental disorders. PLoS ONE 7: e46604.

Crampton SJ, O'Keeffe GW. 2013. NF-кB: Emerging roles in hippocampal development and function. Int J Biochem Cell Biol 45: 1821-1824.

Dash PK, Hochner B, Kandel ER. 1990. Injection of the cAMP-responsive element into the nucleus of Aplysia sensory neurons blocks long-term facilitation. Nature 345: 718-721.

Da Silva WC, Bonini JS, Bevilaqua LR, Medina JH, Izquierdo I, Cammarota M. 2008. Inhibition of mRNA synthesis in the hippocampus impairs consolidation and reconsolidation of spatial memory. Hippocampus 18: $29-39$.

Debiec J, LeDoux JE. 2006. Noradrenergic signaling in the amygdala contributes to the reconsolidation of fear memory: Treatment implications for PTSD. Ann NY Acad Sci 1071: 521-524.

Debiec J, LeDoux JE, Nader K. 2002. Cellular and systems reconsolidation in the hippocampus. Neuron 36: $527-$ 538.

de la Fuente V, Freudenthal R, Romano A. 2011. Reconsolidation or extinction: Transcription factor switch in the determination of memory course after retrieval. J Neurosci 31: 5562-5573.

Dudai Y. 2012. The restless engram: Consolidations never end. Annu Rev Neurosci 35: 227-247.

Eckel-Mahan KL, Storm DR. 2009. Circadian rhythms and memory: Not so simple as cogs and gears. EMBO Rep 10: 584-591.

Etkin A, Alarcón JM, Weisberg SP, Touzani K, Huang YY, Nordheim A, Kandel ER. 2006. A role in learning for SRF: Deletion in the adult forebrain disrupts LTD and the formation of an immediate memory of a novel context. Neuron 50: 127-143.

Finsterwald C, Alberini CM. 2013. Stress and glucocorticoid receptor-dependent mechanisms in long-term memory: From adaptive responses to psychopathologies. Neurobiol Learn Mem 112: 17-29.

Frankland PW, Ding HK, Takahashi E, Suzuki A, Kida S, Silva AJ. 2006. Stability of recent and remote contextual fear memory. Learn Mem 13: 451-457.

Gao J, Wang WY, Mao YW, Gräff J, Guan JS, Pan L, Mak G, Kim D, Su SC, Tsai LH. 2010. A novel pathway regulates memory and plasticity via SIRT1 and miR-134. Nature 466: $1105-1109$.

Garcia-Osta A, Tsokas P, Pollonini G, Landau EM, Blitzer R, Alberini CM. 2006. MuSK expressed in the brain mediates cholinergic responses, synaptic plasticity, and memory formation. J Neurosci 26: 7919-7932.

Garner AR, Rowland DC, Hwang SY, Baumgaertel K, Roth BL, Kentros C, Mayford M. 2012. Generation of a synthetic memory trace. Science 335: 1513-1516.

Goelet P, Castellucci VF, Schacher S, Kandel ER. 1986. The long and the short of long-term memory: A molecular framework. Nature 322: 419-422.

Goodrich JA, Kugel JF. 2006. Non-coding-RNA regulators of RNA polymerase II transcription. Nat Rev Mol Cell Biol 7: 612-616.

Gräff J, Joseph NF, Horn ME, Samiei A, Meng J, Seo J, Rei D, Bero AW, Phan TX, Wagner F, et al. 2014. Epigenetic priming of memory updating during reconsolidation to attenuate remote fear memories. Cell 156: 261-276.

Gruart A, Benito E, Delgado-García JM, Barco A. 2012. Enhanced cAMP response element-binding protein activity increases neuronal excitability, hippocampal longterm potentiation, and classical eyeblink conditioning in alert behaving mice. J Neurosci 32: 17431-17441.

Guan Z, Giustetto M, Lomvardas S, Kim JH, Miniaci MC, Schwartz JH, Thanos D, Kandel ER. 2002. Integration of long-term-memory-related synaptic plasticity involves bidirectional regulation of gene expression and chromatin structure. Cell 111: 483-493.

Guan JS, Haggarty SJ, Giacometti E, Dannenberg JH, Joseph N, Gao J, Nieland TJ, Zhou Y, Wang X, Mazitschek R, et al. 2009. HDAC2 negatively regulates memory formation and synaptic plasticity. Nature 459: 55-60.

Gutierrez H, Davies AM. 2011. Regulation of neural process growth, elaboration and structural plasticity by NF- $\mathrm{KB}$. Trends Neurosci 34: 316-325.

Guzowski JF. 2002. Insights into immediate-early gene function in hippocampal memory consolidation using antisense oligonucleotide and fluorescent imaging approaches. Hippocampus 12: 86-104. 
C.M. Alberini and E.R. Kandel

Han JH, Kushner SA, Yiu AP, Cole CJ, Matynia A, Brown RA, Neve RL, Guzowski JF, Silva AJ, Josselyn SA. 2007. Neuronal competition and selection during memory formation. Science 316: 457-460.

Han JH, Kushner SA, Yiu AP, Hsiang HL, Buch T, Waisman A, Bontempi B, Neve RL, Frankland PW, Josselyn SA. 2009. Selective erasure of a fear memory. Science 323. 1492-1496.

Hansen KF, Sakamoto K, Wayman GA, Impey S, Obrietan K. 2010. Transgenic miR132 alters neuronal spine density and impairs novel object recognition memory. PLoS ONE 5: e15497.

Hawk JD, Abel T. 2011. The role of NR4A transcription factors in memory formation. Brain Res Bull 85: 21-29.

Hawk JD, Bookout AL, Poplawski SG, Bridi M, Rao AJ, Sulewski ME, Kroener BT, Manglesdorf DJ, Abel T. 2012. NR4A nuclear receptors support memory enhancement by histone deacetylase inhibitors. J Clin Invest 122: 3593 3602.

Igaz LM, Vianna MR, Medina JH, Izquierdo I. 2002. Two time periods of hippocampal mRNA synthesis are required for memory consolidation of fear-motivated learning. J Neurosci 22: 6781-6789.

Inda MC, Muravieva EV, Alberini CM. 2011. Memory retrieval and the passage of time: From reconsolidation and strengthening to extinction. J Neurosci 31: 1635-1643.

Jarome TJ, Lubin FD. 2013. Histone lysine methylation: Critical regulator of memory and behavior. Rev Neurosci 24: 375-387.

Josselyn SA, Nguyen PV. 2005. CREB, synapses and memory disorders: Past progress and future challenges. Curr Drug Targets CNS Neurol Disord 4: 481-497.

Josselyn SA, Shi C, Carlezon WA Jr, Neve RL, Nestler EJ, Davis M. 2001. Long-term memory is facilitated by cAMP response element-binding protein overexpression in the amygdala. J Neurosci 21: 2404-2412.

Kaltschmidt B, Ndiaye D, Korte M, Pothion S, Arbibe L, Prüllage M, Pfeiffer J, Lindecke A, Staiger V, Israël A, et al. 2006. NF- $\kappa$ B regulates spatial memory formation and synaptic plasticity through protein kinase A/CREB signaling. Mol Cell Biol 26: 2936-2946.

Kandel ER. 2001. The molecular biology of memory storage: A dialog between genes and synapses. Biosci Rep 200121 : 565-611.

Kandel ER. 2012. The molecular biology of memory: cAMP, PKA, CRE, CREB-1, CREB-2, and CPEB. Mol Brain 5: 14

Kandel ER, Dudai Y, Mayford MR. 2014. The molecular and systems biology of memory. Cell 157: 163-186.

Kida S. 2012. A functional role for CREB as a positive regulator of memory formation and LTP. Exp Neurobiol 21: $136-140$.

Kim TK, Hemberg M, Gray JM, Costa AM, Bear DM, Wu J, Harmin DA, Laptewicz M, Barbara-Haley K, Kuersten S, et al. 2010. Widespread transcription at neuronal activity-regulated enhancers. Nature 465: 182-187.

Klein ME, Lioy DT, Ma L, Impey S, Mandel G, Goodman RH. 2007. Homeostatic regulation of MeCP2 expression by a CREB-induced microRNA. Nat Neurosci 10: $1513-$ 1514.
Knöll B, Nordheim A. 2009. Functional versatility of transcription factors in the nervous system: The SRF paradigm. Trends Neurosci 32: 432-442.

Korzus E, Rosenfeld MG, Mayford M. 2004. CBP histone acetyltransferase activity is a critical component of memory consolidation. Neuron 42: 961-972.

Lee JA, Kim HK, Kim KH, Han JH, Lee YS, Lim CS, Chang DJ, Kubo T, Kaang BK. 2001. Overexpression of and RNA interference with the CCAAT enhancer-binding protein on long-term facilitation of Aplysia sensory to motor synapses. Learn Mem 8: 220-226.

Levenson JM, Sweatt JD. 2005. Epigenetic mechanisms in memory formation. Nat Rev Neurosci 6: 108-118.

Levenson JM, Sweatt JD. 2006. Epigenetic mechanisms: A common theme in vertebrate and invertebrate memory formation. Cell Mol Life Sci 63: 1009-1016.

Lin Y, Bloodgood BL, Hauser JL, Lapan AD, Koon AC, Kim TK, Hu LS, Malik AN, Greenberg ME. 2008. Activitydependent regulation of inhibitory synapse development by Npas4. Nature 455: 1198-1204.

Lopez de Armentia M, Jancic D, Olivares R, Alarcon JM, Kandel ER, Barco A. 2007. cAMP response element-binding protein-mediated gene expression increases the intrinsic excitability of CA1 pyramidal neurons. J Neurosci 27: 13909-13918.

Lopez-Atalaya JP, Gervasini C, Mottadelli F, Spena S, Piccione M, Scarano G, Selicorni A, Barco A, Larizza L. 2012. Histone acetylation deficits in lymphoblastoid cell lines from patients with Rubinstein-Taybi syndrome. J Med Genet 49: 66-74.

Lu Y, Christian K, Lu B. 2008. BDNF: A key regulator for protein synthesis-dependent LTP and long-term memory? Neurobiol Learn Mem 89: 312-323.

Lynch MA. 2004. Long-term potentiation and memory. Physiol Rev 84: 87-136.

Maddox SA, Monsey MS, Schafe GE. 2010. Early growth response gene 1 (Egr-1) is required for new and reactivated fear memories in the lateral amygdala. Learn Mem 18: $24-38$.

Magill ST, Cambronne XA, Luikart BW, Lioy DT, Leighton BH, Westbrook GL, Mandel G, Goodman RH. 2010. microRNA-132 regulates dendritic growth and arborization of newborn neurons in the adult hippocampus. Proc Natl Acad Sci 107: 20382-20387.

Martin KC, Michael D, Rose JC, Barad M, Casadio A, Zhu H, Kandel ER. 1997. MAP kinase translocates into the nucleus of the presynaptic cell and is required for longterm facilitation in Aplysia. Neuron 18: 899-912.

Maze I, Noh KM, Allis CD. 2013. Histone regulation in the CNS: Basic principles of epigenetic plasticity. Neuropsychopharmacology 38: 3-22.

McGaugh JL. 2000. Memory-A century of consolidation. Science 287: 248-251.

Mercer TR, Dinger ME, Mariani J, Kosik KS, Mehler MF, Mattick JS. 2008. Noncoding RNAs in long-term memory formation. Neuroscientist 14: 434-445.

Merlo E, Freudenthal R, Maldonado H, Romano A. 2005. Activation of the transcription factor NF- $\mathrm{kB}$ by retrieval is required for long-term memory reconsolidation. Learn Mem 12: 23-29. 
Milekic MH, Alberini CM. 2002. Temporally graded requirement for protein synthesis following memory reactivation. Neuron 36: 521-525.

Miller CA, Sweatt JD. 2007. Covalent modification of DNA regulates memory formation. Neuron 53: 857-869.

Morris MJ, Mahgoub M, Na ES, Pranav H, Monteggia LM. 2013. Loss of histone deacetylase 2 improves working memory and accelerates extinction learning. J Neurosci 33: 6401-6411.

Nader K, Einarsson EO. 2010. Memory reconsolidation: An update. Ann NY Acad Sci 1191: 27-41.

Nestler EJ. 1993. Cellular responses to chronic treatment with drugs of abuse. Crit Rev Neurobiol 7: 23-39.

Nestler EJ. 2013. Cellular basis of memory for addiction. Dialogues Clin Neurosci 15: 431-443.

Nudelman AS, DiRocco DP, Lambert TJ, Garelick MG, Le J, Nathanson NM, Storm DR. 2010. Neuronal activity rapidly induces transcription of the CREB-regulated microRNA-132, in vivo. Hippocampus 20: 492-498.

Park E, Kim Y, Ryu H, Kowall NW, Lee J, Ryu H. 2014. Epigenetic mechanisms of Rubinstein-Taybi syndrome. Neuromolecular Med 16: 16-24.

Pedreira ME, Dimant B, Maldonado H. 1996. Inhibitors of protein and RNA synthesis block context memory and long-term habituation in the crab Chasmagnathus. Pharmacol Biochem Behav 54: 611-617.

Peixoto L, Abel T. 2013. The role of histone acetylation in memory formation and cognitive impairments. Neuropsychopharmacology 38: 62-76.

Peña de Ortiz S, Maldonado-Vlaar CS, Carrasquillo Y. 2000. Hippocampal expression of the orphan nuclear receptor gene hzf-3/nurr1 during spatial discrimination learning. Neurobiol Learn Mem 74: 161-178.

Perazzona B, Isabel G, Preat T, Davis RL. 2004. The role of cAMP response element-binding protein in Drosophila long-term memory. J Neurosci 24: 8823-8828.

Persengiev SP, Green MR. 2003. The role of ATF/CREB family members in cell growth, survival and apoptosis. Apoptosis 8: 225-228.

Phelps EA. 2004. Human emotion and memory: Interactions of the amygdala and hippocampal complex. Curr Opin Neurobiol 14: 198-202.

Quevedo J, Vianna MR, Roesler R, de-Paris F, Izquierdo I Rose SP. 1999. Two time windows of anisomycin-induced amnesia for inhibitory avoidance training in rats: Protection from amnesia by pretraining but not pre-exposure to the task apparatus. Learn Mem 6: 600-607.

Rajasethupathy P, Antonov I, Sheridan R, Frey S, Sander C, Tuschl T, Kandel ER. 2012. A role for neuronal piRNAs in the epigenetic control of memory-related synaptic plasticity. Cell 149: 693-707.

Ramamoorthi K, Fropf R, Belfort GM, Fitzmaurice HL, McKinney RM, Neve RL, Otto T, Lin Y. 2011. Npas4 regulates a transcriptional program in CA3 required for contextual memory formation. Science 334: 1669-1675.

Ramanan N, Shen Y, Sarsfield S, Lemberger T, Schütz G, Linden DJ, Ginty DD. 2005. SRF mediates activity-induced gene expression and synaptic plasticity but not neuronal viability. Nat Neurosci 8: 759-767.
Ramirez S, Liu X, Lin PA, Suh J, Pignatelli M, Redondo RL, Ryan TJ, Tonegawa S. 2013. Creating a false memory in the hippocampus. Science 341: 387-391.

Reijmers LG, Perkins BL, Matsuo N, Mayford M. 2007. Localization of a stable neural correlate of associative memory. Science 317: 1230-1233.

Rogerson T, Cai DJ, Frank A, Sano Y, Shobe J, Lopez-Aranda MF, Silva AJ. 2014. Synaptic tagging during memory allocation. Nat Rev Neurosci 15: 157-169.

Romano A, Freudenthal R, Merlo E, Routtenberg A. 2006. Evolutionarily conserved role of the NF- $\kappa$ B transcription factor in neural plasticity and memory. Eur J Neurosci 24: 1507-1516.

Rudenko A, Tsai LH. 2014. Epigenetic modifications in the nervous system and their impact upon cognitive impairments. Neuropharmacology 80: 70-82.

Sangha S, Scheibenstock A, Lukowiak K. 2003. Reconsolidation of a long-term memory in Lymnaea requires new protein and RNA synthesis and the soma of right pedal dorsal 1. J Neurosci 23: 8034-8040.

Sara SJ. 2000. Retrieval and reconsolidation: Toward a neurobiology of remembering. Learn Mem 7: 73-84.

Scott R, Bourtchuladze R, Gossweiler S, Dubnau J, Tully T. 2002. CREB and the discovery of cognitive enhancers. $J$ Mol Neurosci 19: 171-177.

Silva AJ, Kogan JH, Frankland PW, Kida S. 1998. CREB and memory. Annu Rev Neurosci 21: 127-148.

Snow WM, Stoesz BM, Kelly DM, Albensi BC. 2013. Roles for NF- $\kappa B$ and gene targets of NF- $\kappa B$ in synaptic plasticity, memory, and navigation. Mol Neurobiol 49: 757-770.

Squire LR, Barondes S. 1970. Actinomycin-D: Effects on memory at different times after training. Nature 225: $649-650$.

Squire LR, Stark CE, Clark RE. 2004. The medial temporal lobe. Annu Rev Neurosci 27: 279-306.

Suzuki A, Josselyn SA, Frankland PW, Masushige S, Silva AJ, Kida S. 2004. Memory reconsolidation and extinction have distinct temporal and biochemical signatures. $J$ Neurosci 24: 4787-4795.

Swank MW, Sweatt JD. 2001. Increased histone acetyltransferase and lysine acetyltransferase activity and biphasic activation of the ERK/RSK cascade in insular cortex during novel taste learning. J Neurosci 21: $3383-$ 3391.

Taubenfeld SM, Wiig KA, Monti B, Dolan B, Pollonini G, Alberini CM. 2001a. Fornix-dependent induction of hippocampal CCAAT enhancer-binding protein $\beta$ and $\delta$ colocalizes with phosphorylated cAMP response elementbinding protein and accompanies long-term memory consolidation. J Neurosci 21: 84-91.

Taubenfeld SM, Milekic MH, Monti B, Alberini CM. 2001b. The consolidation of new but not reactivated memory requires hippocampal C/EBP $\beta$. Nat Neurosci 4: 813818.

Thut PD, Lindell TJ. 1974. $\alpha$-Amanitin inhibition of mouse brain form II ribonucleic acid polymerase and passive avoidance retention. Mol Pharmacol 10: 146154.

Tong H, Steinert JR, Robinson SW, Chernova T, Read DJ, Oliver DL, Forsythe ID. 2010. Regulation of Kv channel 


\section{C.M. Alberini and E.R. Kandel}

expression and neuronal excitability in rat medial nucleus of the trapezoid body maintained in organotypic culture. J Physiol 588: 1451-1468.

Tononi G, Cirelli C. 2014. Sleep and the price of plasticity: From synaptic and cellular homeostasis to memory consolidation and integration. Neuron 81: 12-34.

Veyrac A, Besnard A, Caboche J, Davis S, Laroche S. 2014 The transcription factor zif268/egr 1, brain plasticity, and memory. Prog Mol Biol Transl Sci 122: 89-129.

Viosca J, Lopez de Armentia M, Jancic D, Barco A. 2009. Enhanced CREB-dependent gene expression increases the excitability of neurons in the basal amygdala and primes the consolidation of contextual and cued fear memory. Learn Mem 16: 193-197

Wang G, Grone B, Colas D, Appelbaum L, Mourrain P. 2011. Synaptic plasticity in sleep: Learning, homeostasis and disease. Trends Neurosci 34: 452-463.

Weaver IC, Cervoni N, Champagne FA, D’Alessio AC, Sharma S, Seckl JR, Dymov S, Szyf M, Meaney MJ. 2004. Epigenetic programming by maternal behavior. Nat Neurosci 7: 847-854.
Wetzel W, Ott T, Matthies H. 1976. Is actinomycin D suitable for the investigation of memory processes? Pharmacol Biochem Behav 4: 515-519.

Wiltgen BJ, Tanaka KZ. 2013. Systems consolidation and the content of memory. Neurobiol Learn Mem 106: 365 371.

Wood MA, Hawk JD, Abel T. 2006. Combinatorial chromatin modifications and memory storage: A code for memory? Learn Mem 13: 241-244.

Yin JC, Tully T. 1996. CREB and the formation of long-term memory. Curr Opin Neurobiol 6: 264-268.

Yin JCP, Wallach JS, Del Vecchio M, Wilder EL, Zhou H, Quinn WG, Tully T. 1994. Induction of a dominant-negative CREB transgene specifically blocks long-term memory in Drosophila melanogaster. Cell 79: 49-58.

Zhou Y1, Won J, Karlsson MG, Zhou M, Rogerson T, Balaji J, Neve R, Poirazi P, Silva AJ. 2009. CREB regulates excitability and the allocation of memory to subsets of neurons in the amygdala. Nat Neurosci 12: 1438-1443.

Zovkic IB, Guzman-Karlsson MC, Sweatt JD. 2013. Epigenetic regulation of memory formation and maintenance. Learn Mem 20: 61-74. 


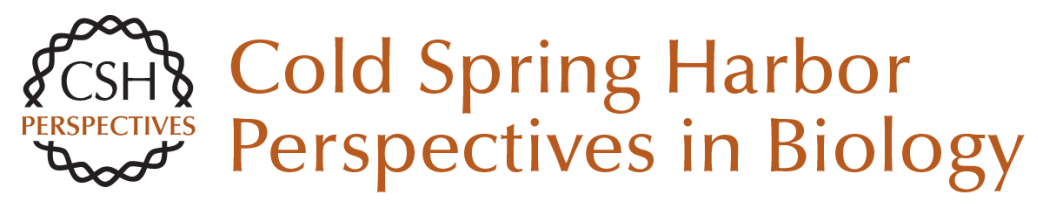

\section{The Regulation of Transcription in Memory Consolidation}

Cristina M. Alberini and Eric R. Kandel

Cold Spring Harb Perspect Biol 2015; doi: 10.1101/cshperspect.a021741 originally published online December 4, 2014

\section{Subject Collection Learning and Memory}

Large-Scale Fluorescence Calcium-Imaging Methods for Studies of Long-Term Memory in Behaving Mammals Pablo Jercog, Thomas Rogerson and Mark J. Schnitzer

Exploring Memory Representations with

Activity-Based Genetics Mark Mayford and Leon Reijmers

The Origins and Organization of Vertebrate Pavlovian Conditioning Michael S. Fanselow and Kate M. Wassum

The Corticohippocampal Circuit, Synaptic Plasticity, and Memory Jayeeta Basu and Steven A. Siegelbaum

Motor Learning and the Cerebellum Chris I. De Zeeuw and Michiel M. Ten Brinke

The Striatum: Where Skills and Habits Meet Ann M. Graybiel and Scott T. Grafton

Molecular Genetic Strategies in the Study of Corticohippocampal Circuits Christopher C. Angelakos and Ted Abel

Nonassociative Learning in Invertebrates John H. Byrne and Robert D. Hawkins
The Role of Functional Prion-Like Proteins in the Persistence of Memory Kausik Si and Eric R. Kandel

Working Memory: Maintenance, Updating, and the Realization of Intentions Lars Nyberg and Johan Eriksson

Memory Retrieval in Mice and Men Aya Ben-Yakov, Yadin Dudai and Mark R. Mayford

Reconsolidation and the Dynamic Nature of Memory Karim Nader

Memory Consolidation Larry R. Squire, Lisa Genzel, John T. Wixted, et al.

Structural Components of Synaptic Plasticity and Memory Consolidation Craig H. Bailey, Eric R. Kandel and Kristen M. Harris

Associative Learning in Invertebrates Robert D. Hawkins and John H. Byrne

The Regulation of Transcription in Memory Consolidation Cristina M. Alberini and Eric R. Kandel

For additional articles in this collection, see http://cshperspectives.cshlp.org/cgi/collection/

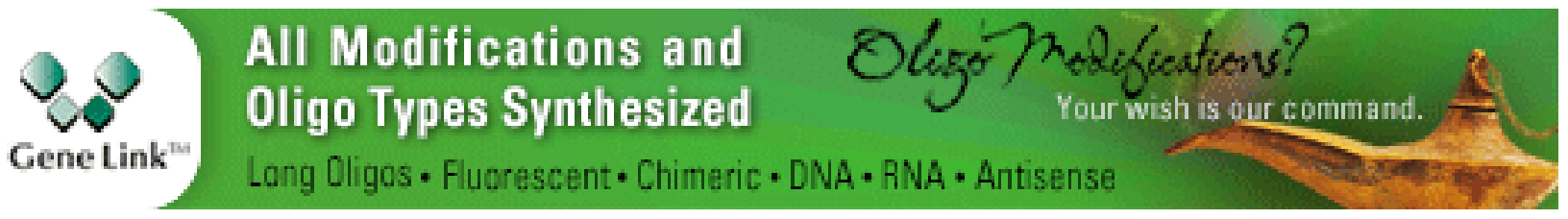

